\title{
Empowering citizen scientists
}

\author{
Scientists should consider engaging more with the DIYbio community.
}

A scientifically literate general public ranks high on the wish list of biological researchers. According to a poll taken at a recent synthetic biology conference, scientists see a public uninformed about biotechnology as a threat to their work. Instead they want the 'man on the street' to understand and support what goes on in the lab. In our June Editorial we discussed different routes used to disseminate scientific information. We now want to encourage our readers to get involved in venues that give lay people a chance to get hands-on experience in biology: DIYbio labs.

These do-it-yourself (DIY) biology labs are organized and run locally, often by scientists who work on a volunteer basis. Their rationale, as Ellen Jorgensen-cofounder of Genspace in Brooklyn, New York-sums up in a TED talk, was to expand the use of biotechnology beyond the professionals and to put the tools in the hands of lay people to use in fun and creative ways.

Members of the DIYbio community, also known as biohackers, come from different educational and socioeconomic backgrounds; some have scientific training, but many do not. They span vast age ranges, from 11 year olds to retirees, but what unites them is the desire to demystify biology, particularly molecular biology. Inspired by the revolution in electronics in the 20th century, they want to see similar developments in biology.

The funding comes from donations, and crowdsourcing is often used to raise money for the initial costs. Once a DIYbio lab has reached a critical mass, it is sustained by membership fees and sometimes grants.

Over the past eight years, the movement has grown into an ever-expanding international community. DIYbio.org, founded in 2008 by Harvard- and MIT-trained scientists Jason Bobe and Mackenzie Cowell, is a public resource for information about local community labs and advice on how to start a lab or troubleshoot protocols.

The thought of people genetically modifying organisms in a community lab can evoke safety concerns. But such fears stem from a misunderstanding of what takes place in DIYbio labs. Citizen scientists do not work with pathogens, and they operate in an open environment in which everybody is curious about each other's projects and goals. DIYbio labs in the Europe and North America formulated a DIYbio code of ethics and follow community standards for aspects such as waste disposal. In the United States, the Federal Bureau of Investigation's weapons of mass destruction directorate is in contact with some of the organizers of DIYbio labs, has organized joint conferences and, as stated by more than one DIYbio lab organizer, is not worried about their activities.

DIYbio labs often have a three-pronged approach. Talks about current topics given by scientists seek to engage the public in a dialogue. The attendees receive information and have a chance to voice their concerns and objections, and the scientists take back a better understanding of how their work is perceived. Workshops and courses with illustrative titles such as "Biohacker Boot Camp" introduce the attendees to basic laboratory techniques. Labs also offer membership that allows one to pursue an individual project. These projects have included goals as diverse as making art with bacteria, designing a bacteria-based $3 \mathrm{D}$ printer, making vegan cheese and matching dog waste to its owner.

The scientific community can support the movement in different ways. The most obvious first step is to find out about a DIYbio lab in one's neighborhood and visit. Offers to give talks, help with workshops or mentor on a project are also likely to be much appreciated.

Aside from time, more tangible contributions, such as donating old lab equipment, are another way to get involved. The London Biohackspace team, for example, spent about a year outfitting their lab and were very grateful for the support of scientists at different universities who donated scales and centrifuges.

At a time of increased emphasis on STEM (science, technology, engineering and math) education in schools, DIYbio labs can be ideal grounds for high school students to gain laboratory experience. Genspace, for example, hosts a team of high schoolers who entered the iGEM (International Genetically Engineered Machine) competition, an event that requires participants to submit a proposal for the design of a genetically engineered biological system using standard parts. MadLab in Manchester, UK, runs workshops for science-curious amateurs including high school students. Asa Calow, one of the organizers, is inspired by the BBC's micro:bit project, a pocket-sized codable computer that will be given to every year 7 student across the UK to stimulate digital creativity. $\mathrm{He}$ wants to see the same thing happen in biology; providing safe spaces where students_of any age-can experiment is a start.

Go check it out. 